\title{
A MULTI-OBJECTIVE APPROACH FOR LAND CONSERVATION CAPABILITY EVALUATION USING MULTI-CRITERION EVALUATION MODELS
}

\author{
RAHDARI, V..$^{1, *}$ - SOFFIANIAN, A. R. ${ }^{1}$ - POURMANAFI, S. ${ }^{1}$ - GHAIUMI, M. H. ${ }^{3}$ - MOSADEGHI, R. ${ }^{4}-$ \\ AMIRI, F. \\ ${ }^{I}$ Natural Resource Faculty, Isfahan University of Technology \\ Isfahan, Iran \\ ${ }^{2}$ Natural Resource Faculty, Zabol University \\ Zabol, Iran \\ ${ }^{3}$ Soil \& Geomorphology Department, Iranian Soil and Water Research Institute \\ Isfahan Branch, Iran \\ ${ }^{4}$ Griffith Centre for Coastal Management, Griffith University \\ Queensland 4222, Australia \\ ${ }^{5}$ Natural Resource Faculty, Islamic Azad University \\ Bushehr Branch, Iran \\ *Corresponding author \\ e-mail:v.rahdary@gmail.com; phone: +98-915-341-0168 \\ (Received $21^{\text {st }}$ Sep 2017; accepted $15^{\text {th }}$ Jan 2018)
}

\begin{abstract}
In order to protect ecosystem functions and structures, it is essential to identify areas with high conservation potentials. The present study investigates the use of Multi-Criteria Evaluation (MCE) Models and effects of trade-off levels on the results of land conservation capability in the Pelasjan subbasin, western part of the Gavkhooni watershed and Gavkhooni wetland water source in central Iran. Delphi survey method was used to gather, condense and use experts' knowledge in determining and ranking the evaluation criteria. Analytic Hierarchy Process (AHP) was then used to estimate the criteria weights. Subsequently, to create a single ranked map of potential conservation area, a weighted linear combination (WLC) model and ordered weighted averaging (OWA) model with medium risk and tradeoff were used. Conservation capability maps, were then classified into 6 classes based on conservation capability values ranges. The comparison analysis has shown that designed OWA model with lower trade-off level leads to relate areas as very high and high capability classes. Models accuracy assessments have shown that OWA model was more accurate and realistic, but with regard to Plasjan's importance as a habitat for fauna and flora, producing water, and high quality soil and biodiversity, it is highly necessary to consider WLC results.
\end{abstract}

Keywords: AHP, fuzzy, Gavkhooni wetland, OWA, Plasjan sub-basin, trade-off, WLC

\section{Introduction}

For effective land conservation, suitable areas should be determined by considering multiple factors including ecological and natural systems, social and economic criteria and existing land uses (Bryan et al., 2009; Alexander and Sahotra, 2006; Mousavi et al., 2015; Farrashi et al., 2016). This complexity has triggered considerable interest in applying quantitative methods such as Multi-criteria decision-making (MCDM) techniques to these problems (Ananda and Herath, 2009; Chen et al., 2010; Mosadeghi, 2013). 
MCDM techniques combined with GIS have been successfully applied in a number of land capability analyses, environmental planning and management studies. Using spatial MCDM techniques can improve the transparency and analytic rigor of the land capability analysis including land conservation allocation (Jiang and Eastman, 2000; Malczewski, 2006b; Mosadeghi et al., 2015; Villacreses et al., 2017). Multi-criteria evaluation (MCE) is a subdivision of MCDM, which can use and combine different criteria to evaluate land capabilities for each land use. In MCE models, the weights and relative importance of different criteria are considered unequal. Different MCE techniques use different algorithms to assign weight at either the cardinal or ordinal level of measurement (Hajkowicz and Collins, 2007; Mosadeghi, 2013). For the purpose of this study, Analytical Hierarchical Process (AHP) is used to rank the importance of each capability criterion. The AHP was used due to the following benefits: (1) it is well-known and well-reviewed in the literature; (2) it includes an efficient criterion weighting process of pair-wise comparison; (3) it incorporates hierarchical description of criterion which keeps the number pair-wised comparison manageable; and (4) its use is facilitated by available software (Satty, 1994; Norris and Marshal, 1995; Kristof, 2005; Chakhar and Mousseau, 2008; Ho, 2008; Drobne and Lisec, 2009; Moeinaddini et al., 2010; Hajehforooshnia et al., 2011; Mosadeghi, 2013; Sánchez et al., 2013; Mosadeghi et al., 2015; Farashi et al., 2016; Allaouia et al., 2018).

The study also explores the use of two different MCE operators, weighted linear combination (WLC) and ordered weighted averaging (OWA) in producing the final suitability maps.

In MCE model, a criterion with a higher weight can compensate for the weakness of other criteria with lower weights in a spatial position. In MCE process, trade-off is related to capability of compensating for the weakness of a criterion with other criteria. With increasing amount of trade-off in MCE model, more areas will be considered as high capability areas whose amounts of risk and trade-off would be determined by decision-makers. Weighted linear combination (WLC) and ordered weighted averaging (OWA) are two useful methods for land capability evaluation (Seok, 2008; Chen and Paydar, 2012; Mokarram and Hojati, 2017; Villacreses et al., 2017). OWA is a combined technique in which users can control risk and trade-off levels by considering objects and land condition (Parhizkar, 2011; Mousavia et al., 2014). OWA uses a class of multi-criteria operators and involves two sets of weights: Original criteria weights and ordered weights (Malcezewski, 2006; Makropoulos; 2006; Boroushaki and Malczewski, 2008; Chen and Paydar, 2012; Chen et al.,2013; Sánchez et al., 2013; Zavadskas et al., 2015; Mokarram and Hojati, 2017; Villacreses et al., 2017). The former are assigned to a given criterion for all locations in a study area to indicate their relative importance (Seok, 2008; Ali Yahyai et al., 2012; Chen and Paydar, 2012; Allaouia et al., 2018). For calculating the ordered weights, at first layers would be ordered by paying attention to their original weights in an increasing trend and then ordered weights would be assigned with values between (1) and (0). If (1) is assigned to the first criterion with the lowest original weight and (0) is assigned to other layers, the model has no risk and trade-off; and if 1 is assigned to the last criterion with the highest original weight and 0 is assigned to other layers, the model has the highest risk and no trade-off. When numbers between (0) and (1) are assigned to all criteria, the model has a range of risk and trade-off (Malcezewski, 2006; Sánchez-Lozano et al., 2013; Mokarram and Hojati, 2017). 
Therefore, it is possible to control the risk and trade-off in OWA model through a set of ordered weights for each criterion at every location (pixel) (Malcezewski, 2006b; Ahn, 2008; Boroushaki and Malczewski, 2008; Chen and Paydar, 2012; Chen et al., 2013; Mosavi and Yazdani, 2014; Allaouia et al., 2018; Mokarram and Hojati, 2017). Decision area is triangular, which in fact, any assignment of ordered weights results in a decision rule that falls somewhere in a triangular decision strategy space defined by the dimensions of risk and trade-off (Drobne and Lisec, 2009; Mokarram and Hojati, 2017). WLC is an MCE method with the highest trade-off and medium risk (Malcezewski, 2006b; Ahn, 2008; Boroushaki and Malczewski, 2008; Drobne and Lisec, 2009; Moeinaddini et al., 2010; Ali Yahyai et al., 2012; Allaouia et al., 2018; Mokarram and Hojati, 2017). Figure 1 shows decision area triangles.

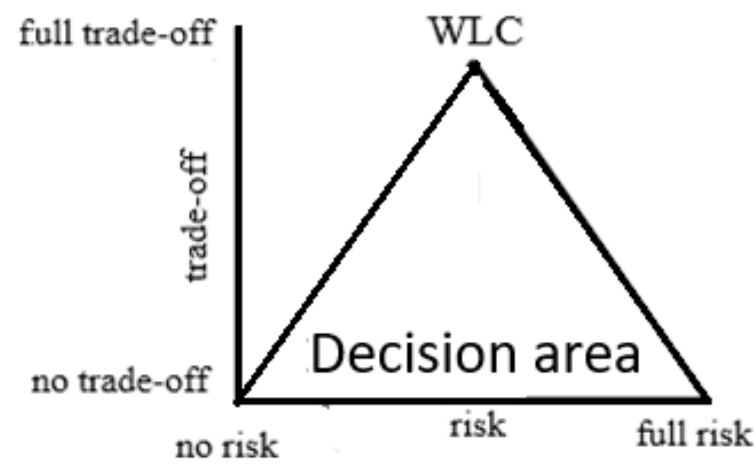

Figure 1. Decision area, risk and trade-off (Mokarram and Hojati, 2017)

In most studies, effects of trade-off were not considered and also were mostly focused on ecological parameters. In this study, for producing proper conservation capability models, we considered a set of ecological, social and economic criteria. The objective of this study is to produce land conservation capability models with WLC and OWA methods and to investigate trade-off effects on multi-criteria land evaluation results. In this case, we used different levels of trade-off using WLC and OWA models to produce conservation capability models for Gavkhooni wetland water source (Pelasjan sub-basin).

\section{Materials and methods}

\section{The study area}

The study area was Pelasjan sub-basin including the western part of the Gavkhooni watershed located in central Iran covering approximately 412,999 ha. The Zayandehrood is the major river in Gavkhooni watershed to which Pelasjan sub-basin gives the highest portion of water. The Gavkhooni wetland is located in the eastern part of Gavkhooni watershed and is the terminal basin of the Zayandehrood River. Pelasjan sub-basin's average temperature is $8-13{ }^{\circ} \mathrm{C}$ with $400-1250 \mathrm{~mm}$ precipitation. Agricultural activities and animal husbandry are the main activities of people living in these areas. Figure 2 shows the location of the Zayanderood River Basin and Pelasjan sub-basin in the western part of the Gavkhooni wetland in Iran. 


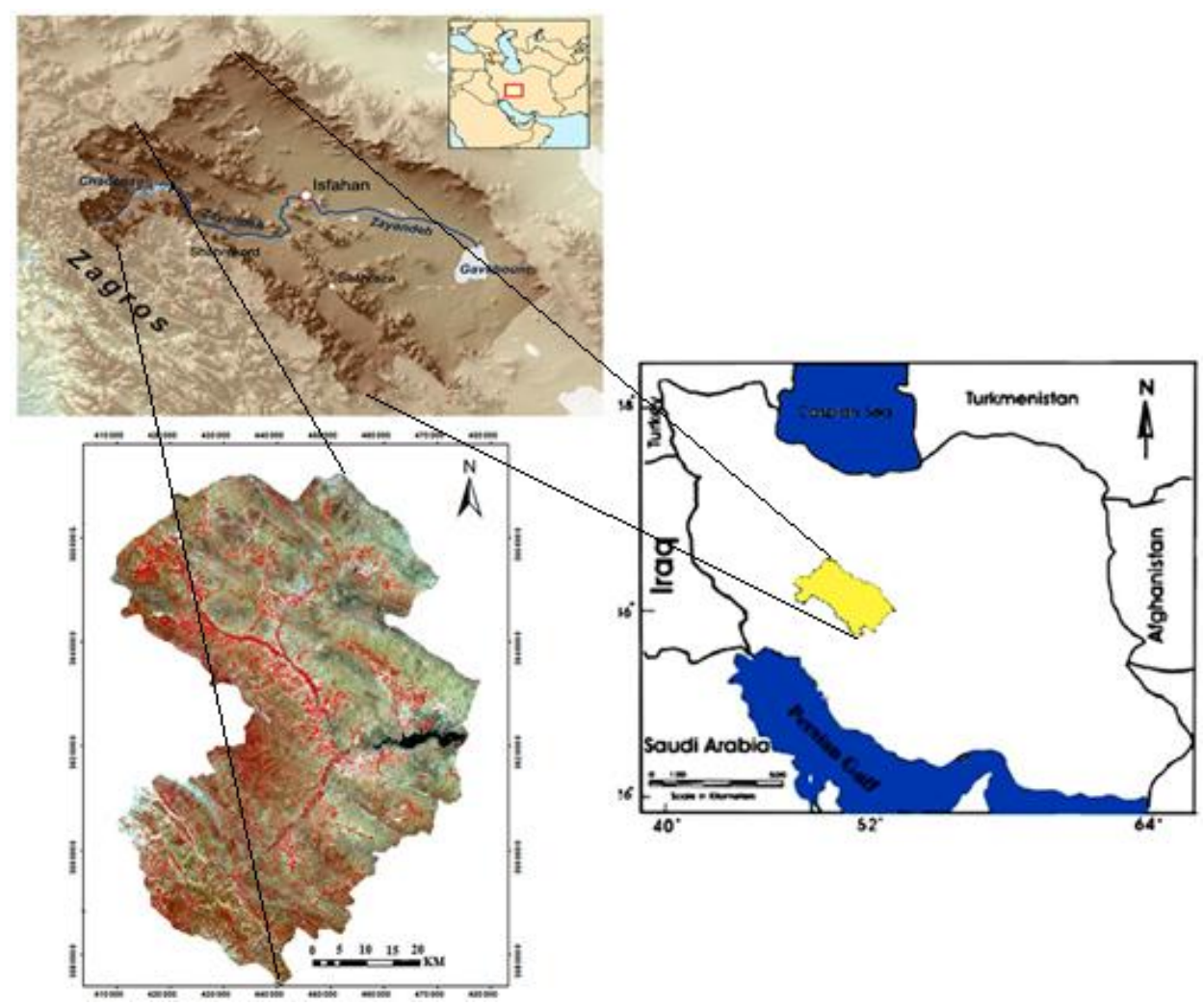

Figure 2. Pelasjan sub-basin located in the western part of Gavkhooni wetland

\section{Data selection}

For data selection, at first, literatures about different aspects of conservation were reviewed. Then, with 21 questionnaires, expert opinions were given using Delphi method in 3 steps, and appropriate data were determined. Experts were selected based on their experience and knowledge in biodiversity, hydrology and soil. For producing an LULC map, Landsat 8 and OLI sensor images for June 2016 were prepared. Other layers were selected from the Isfahan University of Technology archives produced in 2016. With regard to the literature review and expert's knowledge, a study's hierarchy scheme was designed (Fig. 3).

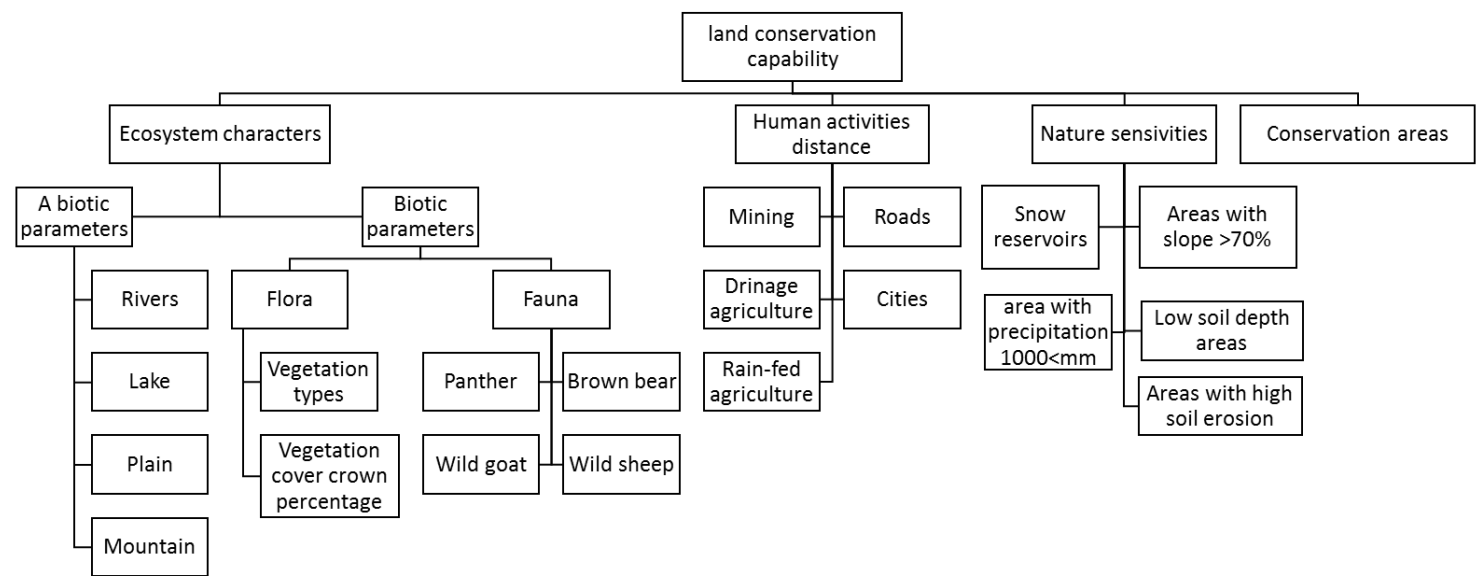

Figure 3. Hierarchical system designed for study 


\section{Field sampling}

According to the phenology of natural vegetation in rangelands and agricultural crops, plant field sampling was conducted in June 2016, and 210 samples of LULC were recorded using GPS. The collected samples were used for producing LULC maps and accuracy assessment.

\section{Data pre-processing}

Atmospheric and radiometric corrections were performed on satellite images with FLASH method. All criteria geo-referencing was controlled using 25 control points with the nearest neighbor method.

\section{Developing LULC maps}

To produce an LULC map, OLI sensor images were classified using the hybrid classification method (Estman, 2001) on each image. The LULC map was produced in 8 classes. Conservation area borders were added as the eighth class. The accuracy of LULC map was determined by calculating the kappa index and overall accuracy. Then, the layers of LULC map were utilized in capability models evaluation.

\section{Criteria standardization}

By paying attention to literature review and expert knowledge, all criteria were standardized between zero and 255, and constraints were standardized using the Boolean method (Malczewski, 2004; Mirghaed et al., 2014). Appropriate Fuzzy functions and their thresholds were determined for each criterion with literature review and expert knowledge.

\section{Criteria's weights calculating}

AHP method was applied to calculate the criteria weights. For this purpose, criteria, sub-criteria and indices were compared in a pairwise method provided by experts in the research questionnaire, and the final weights were calculated according to a hierarchical structure in expert choice softer version 11 (Fig. 3). In this way, the accuracy of pairwise comparisons was determined by calculating the coefficient of consistency, and questionnaires that had more than 0.1 errors were returned to the interviewers to be improved. Finally, the weights of all considered criteria, sub-criteria, indices and subindices were calculated.

\section{Layers combination using WLC and OWA methods}

To combine the individual suitability layers for each criterion, two combination operators, WLC and OWA methods, were used according to Figure 3. The layers, from the lowest branches were combined by applying their weights in each branch based on Equation 1 (Malcezewski, 2006b; Ahn, 2008; Boroushaki and Malczewski, 2008; Dorbne and Lisec, 2009; Koravand, 2015; Farashi et al., 2016; Mokarram and Hojati, 2017):

$$
S=\sum i=1 \text { to } n W_{i} X_{i} \prod C_{i}
$$


$\mathrm{S}=$ capability degree

$W_{i}=$ each criterion' weight

$X_{i}=$ fuzzy value of i parameter

$\prod=$ multiplication sign

$C_{i}=$ Boolean constraint

In OWA model, layers were ordered by considering their original weights in an increasing trend. Ordered weights were calculated as Equation 2 according to risk and trade-off level (Dorbne and Lisec, 2009; Mokarram and Hojati, 2017).

$$
W i=\left(\frac{1}{n}\right) \alpha
$$

The layers, from the lowest branches were combined by applying their weights in each branch based on Equation 3 (Malczewski, 2006b; Dorbne and Lisec, 2009; Parhizkar, 2011; Mokarram and Hojati, 2017).

$$
O W I i=\sum_{i=1}^{n}\left(\frac{w i v j}{\sum_{i=1}^{n} w i v j}\right) Z i j
$$

$\mathrm{Vj}=$ ordered criterion weight

$\mathrm{Wi}=$ ordinary criterion weight

$\mathrm{Zij}=$ sorted criteria

According to the input data (criterion weights and criterion map layers), the OWA combination operator associates with the i-th location (e.g., raster or point) a set of ordered weights. $\alpha$ risk and trade-off level, $\mathrm{n}$ rank of each criterion and $\alpha=0.5$ (Moosavi and Yazdani, 2014; Morshedi and Kooravand, 2015). In the WLC and OWA models, all standardized Boolean constraints were done.

In this study, decision area is a right triangle on the left of the main decision-making triangle, which designed OWA decision area, is Trapezius in WLC decision area, and the area of designed OWA model in the study is less than the WLC model.

Figure 4 shows the decision area in this study.

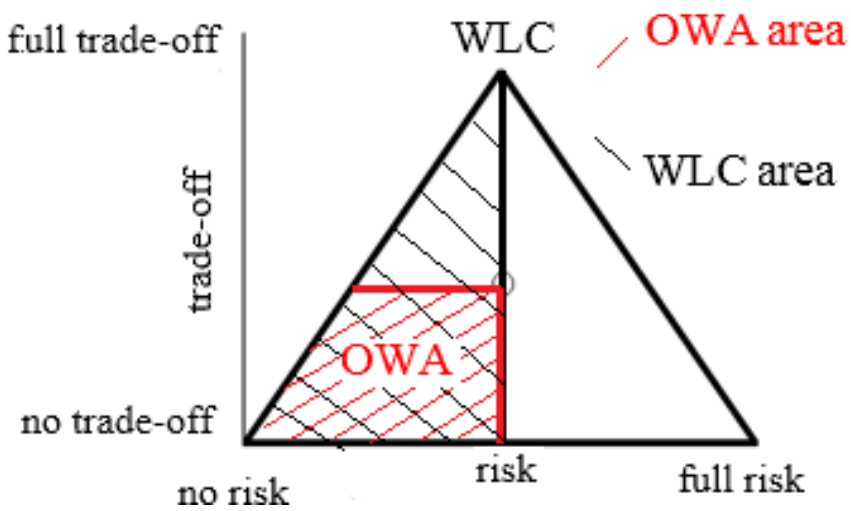

Figure 4. Decision area in this study 


\section{Conservation capability model classification}

Each model was classified into 6 classes with calculating standard deviation and its average according to Table 1 .

Table 1. Definition capability class range

\begin{tabular}{|c|c|c|c|}
\hline $\begin{array}{c}\text { Conservation } \\
\text { capability's class }\end{array}$ & Range & $\begin{array}{c}\text { Conservation } \\
\text { capability's class }\end{array}$ & Range \\
\hline Without capability & 0 & $\begin{array}{l}\text { With medium } \\
\text { capability }\end{array}$ & $\overline{\mathrm{X}}-\mathrm{Sx}<\mathrm{X}<\overline{\mathrm{X}}$ \\
\hline $\begin{array}{l}\text { With very low } \\
\text { capability }\end{array}$ & $0<\mathrm{X}<\mathrm{X}-1.5 *(\mathrm{Sx})$ & With high capability & $\bar{X}<X<\bar{X}+S x$ \\
\hline $\begin{array}{l}\text { With low } \\
\text { capability }\end{array}$ & $\overline{\mathrm{X}}-1.5 *(\mathrm{Sx})<\mathrm{x}<\overline{\mathrm{X}}-\mathrm{Sx}$ & $\begin{array}{c}\text { With very high } \\
\text { capability }\end{array}$ & $\bar{X}+\mathrm{Sx}<\mathrm{X}<\overline{\mathrm{X}}+1.5 \mathrm{Sx}$ \\
\hline
\end{tabular}

$\overline{\mathrm{X}}=$ Average, $\mathrm{Sx}=$ standard deviation

\section{Models accuracy assessment}

For models accuracy assessment, it is supposed that the criterion conservation capability with the highest weigh should have more correlation with the final model result. Therefore, the ecosystems characterizing a criterion which has the highest weight among all criteria was selected, and because it is produced via combination of two sub-criteria, fauna distribution with the highest weight was selected for the assessment of WLC and OWA criterion models. Fauna distribution was divided into 6 class-like models, and in each class, samples were selected and were comprised with final WLC and OWA conservation capability models in IDRISI-Terset software, and total accuracy coefficient was calculated in sampled areas with $125400(30 \times 30)$ pixels from conservation capability classes for conservation capability models via Equation 4 (Estma, 2001).

$$
\text { Overall accuracy }=\frac{\text { Accurated classified pixels }}{\text { Total pixels }}
$$

\section{Results}

LULC map of the area was prepared using Landsat satellite images, OLI sensor, and by applying a hybrid image classification method with overall accuracy of $92 \%$ and the kappa coefficient of 0.88 in 8 classes plus conservation area border (Fig. 5). All layers were standardized using proper Fuzzy functions between 0 and 255. Criteria's weights were calculated using the AHP method. Table 2 shows all used layers' weights and Fuzzy functions.

After calculating original and ordered weights, all layers were combined by applying WLC and OWA models. Figures 6 and 7 show the classified conservation capability maps produced with WLC and OWA methods, respectively, in Table 1. Table 3 presents the area of each conservation capability class as hectare and a percentage of the study area.

In model's results, each class of current LULC in very high and high conservation capability was determined. Figures 8 and 9 show the conversion capability of LULC with very high and high conservation capability classes, respectively. 
Table 2. Conservation layers' weights and fuzzy functions

\begin{tabular}{|c|c|c|c|c|c|c|c|c|}
\hline & $\begin{array}{c}\text { Criteria } \\
\text { weighting }\end{array}$ & $\begin{array}{l}\text { Sub- } \\
\text { criteria }\end{array}$ & $\begin{array}{c}\text { Sub- } \\
\text { criteria } \\
\text { weight }\end{array}$ & Indices & $\begin{array}{l}\text { Indices } \\
\text { weights }\end{array}$ & $\begin{array}{l}\text { Sub- } \\
\text { indices }\end{array}$ & $\begin{array}{c}\text { Sub- } \\
\text { indices } \\
\text { weights }\end{array}$ & $\begin{array}{c}\text { Appropriate } \\
\text { fuzzy } \\
\text { function }\end{array}$ \\
\hline \multirow{10}{*}{$\begin{array}{c}\text { Ecosystems } \\
\text { characteristics }\end{array}$} & \multirow{10}{*}{0.33} & \multirow{6}{*}{$\begin{array}{l}\text { Biotic } \\
\text { elements }\end{array}$} & \multirow{6}{*}{0.55} & \multirow[b]{2}{*}{ Flora } & \multirow[b]{2}{*}{0.41} & $\begin{array}{l}\text { Vegetation } \\
\text { types }\end{array}$ & 0.67 & \multirow[b]{2}{*}{ User defined } \\
\hline & & & & & & $\begin{array}{c}\text { Cover } \\
\text { crown } \\
\text { percentage }\end{array}$ & 0.33 & \\
\hline & & & & \multirow{4}{*}{$\begin{array}{c}\text { Fauna } \\
\text { distribution }\end{array}$} & \multirow{4}{*}{0.59} & Panther & 0.27 & \multirow{4}{*}{$\begin{array}{l}\text { Decreasing } \\
\text { sigmoid }\end{array}$} \\
\hline & & & & & & $\begin{array}{c}\text { Brown } \\
\text { bear }\end{array}$ & 0.32 & \\
\hline & & & & & & $\begin{array}{r}\text { Wild } \\
\text { sheep }\end{array}$ & 0.21 & \\
\hline & & & & & & Wild goat & 0.2 & \\
\hline & & \multirow{4}{*}{$\begin{array}{l}\text { Abiotic } \\
\text { elements }\end{array}$} & \multirow{4}{*}{0.45} & Rivers & 0.33 & & & \multirow{4}{*}{$\begin{array}{l}\text { Decreasing } \\
\text { sigmoid }\end{array}$} \\
\hline & & & & Lakes & 0.29 & & & \\
\hline & & & & Plains & 0.13 & & & \\
\hline & & & & Mountains & 0.25 & & & \\
\hline \multirow{5}{*}{$\begin{array}{l}\text { Human } \\
\text { activities } \\
\text { distance }\end{array}$} & \multirow{5}{*}{0.16} & Mining & 0.21 & & & & & \multirow{5}{*}{$\begin{array}{l}\text { Increasing } \\
\text { sigmoid }\end{array}$} \\
\hline & & Roads & 0.14 & & & & & \\
\hline & & Cities & 0.23 & & & & & \\
\hline & & $\begin{array}{l}\text { Drainage } \\
\text { agriculture }\end{array}$ & 0.12 & & & & & \\
\hline & & $\begin{array}{l}\text { Rain-fed } \\
\text { agriculture }\end{array}$ & 0.1 & & & & & \\
\hline \multirow{4}{*}{$\begin{array}{c}\text { Nature } \\
\text { sensitivities }\end{array}$} & \multirow{4}{*}{0.31} & $\begin{array}{l}\text { Slope } \\
>70 \%\end{array}$ & 0.38 & & & & & User defined \\
\hline & & $\begin{array}{l}\text { Areas } \\
\text { with high } \\
\text { soil } \\
\text { erosion }\end{array}$ & 0.32 & & & & & User defined \\
\hline & & $\begin{array}{l}\text { Snow } \\
\text { reservoirs }\end{array}$ & 0.1 & & & & & $\begin{array}{c}\text { Decreasing } \\
\text { sigmoid }\end{array}$ \\
\hline & & $\begin{array}{c}\text { Areas } \\
\text { with low } \\
\text { soil depth }\end{array}$ & 0.2 & & & & & User defined \\
\hline $\begin{array}{c}\text { Under } \\
\text { conservation } \\
\text { area }\end{array}$ & 0.2 & & & & & & & $\begin{array}{l}\text { Decreasing } \\
\text { sigmoid }\end{array}$ \\
\hline
\end{tabular}

Table 3. Conservation capability area with MCE methods (hectare)

\begin{tabular}{l|c|c|c|c|c}
\hline & $\begin{array}{c}\text { Conservation } \\
\text { capability class }\end{array}$ & WLC area & WLC percentage & OWA area & OWA percentage \\
\hline 1 & Very high & 14722 & 3.52 & 9772 & 2.39 \\
2 & High & 79871 & 19.11 & 60686 & 14.87 \\
3 & Moderate & 204296 & 48.89 & 157976 & 38.73 \\
4 & Low & 85011 & 20.34 & 142297 & 34.87 \\
5 & Very low & 919 & 0.22 & 4188 & 1.03 \\
6 & Without capability & 33105 & 7.92 & 33105 & 8.11 \\
\hline
\end{tabular}




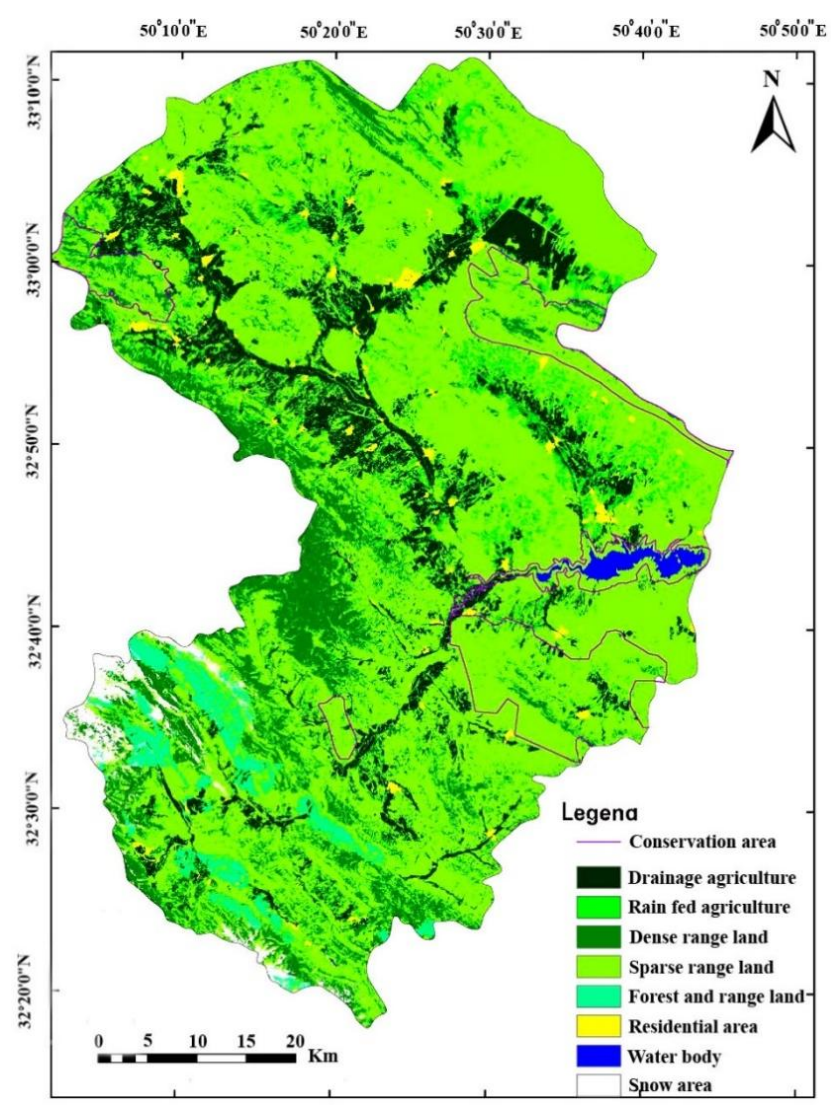

Figure 5. LULC map using OLI image in 2015

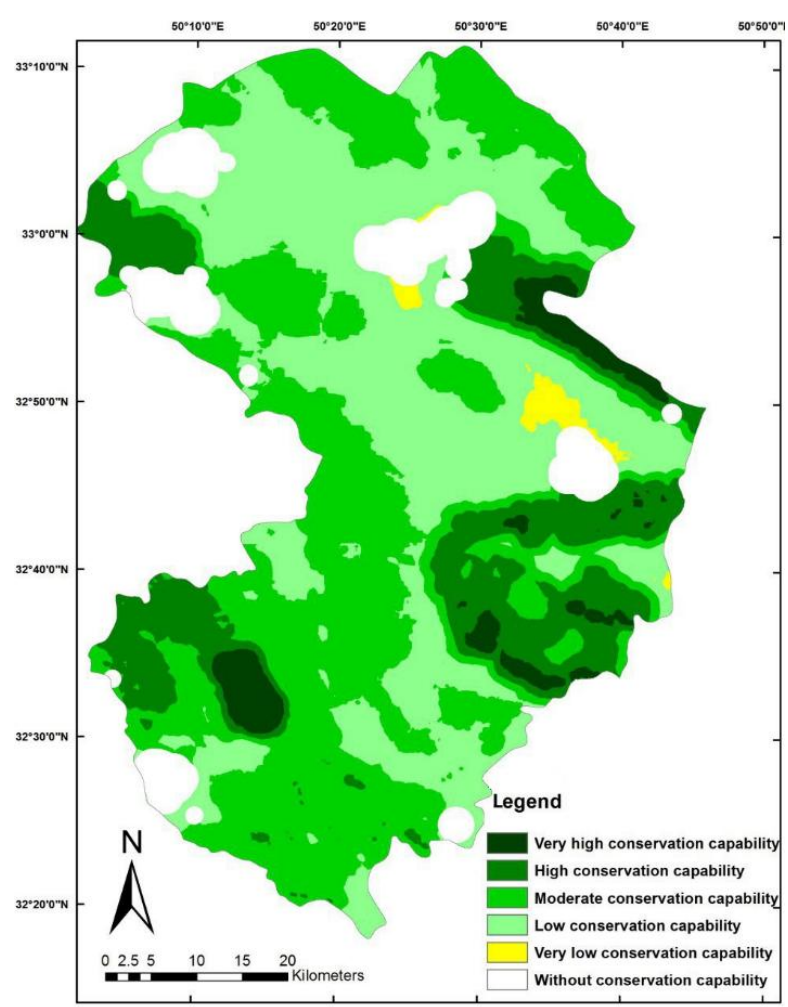

Figure 6. Land capability map with WLC

APPLIED ECOLOGY AND ENVIRONMENTAL RESEARCH 16(2):1353-1367. http://www.aloki.hu • ISSN 15891623 (Print) • ISSN 17850037 (Online) DOI: http://dx.doi.org/10.15666/aeer/1602_13531367 (c) 2018, ALÖKI Kft., Budapest, Hungary 


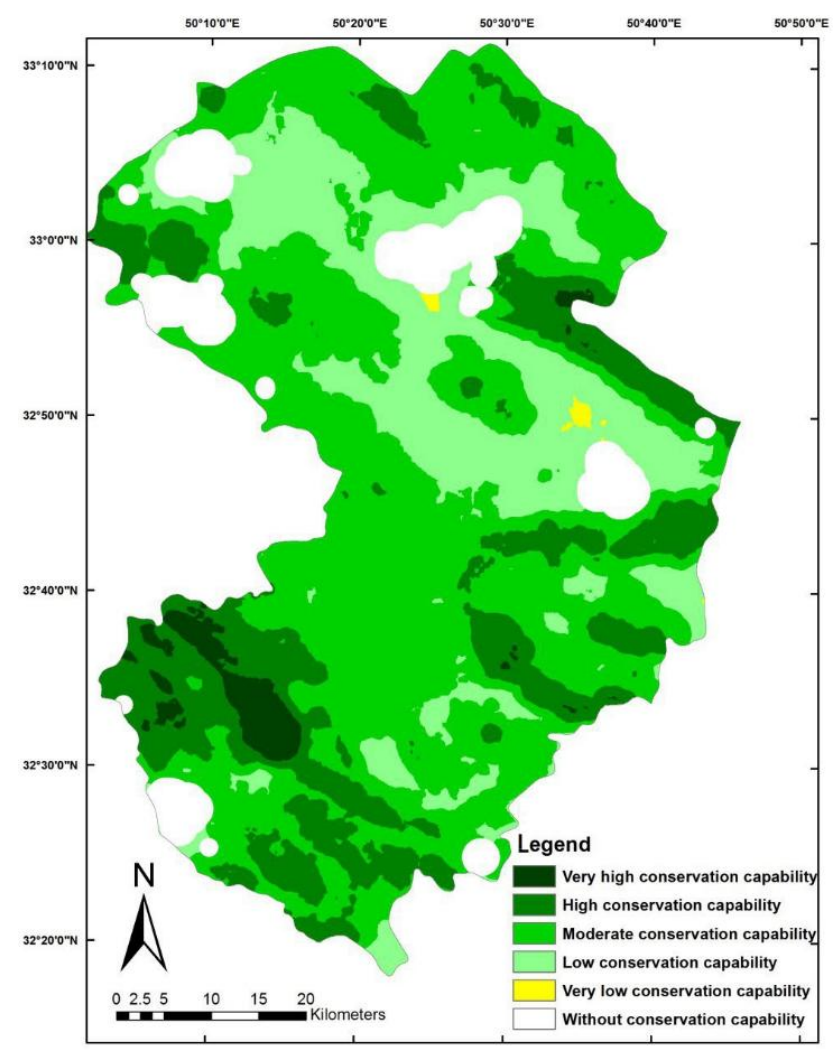

Figure 7. Land capability map with OWA

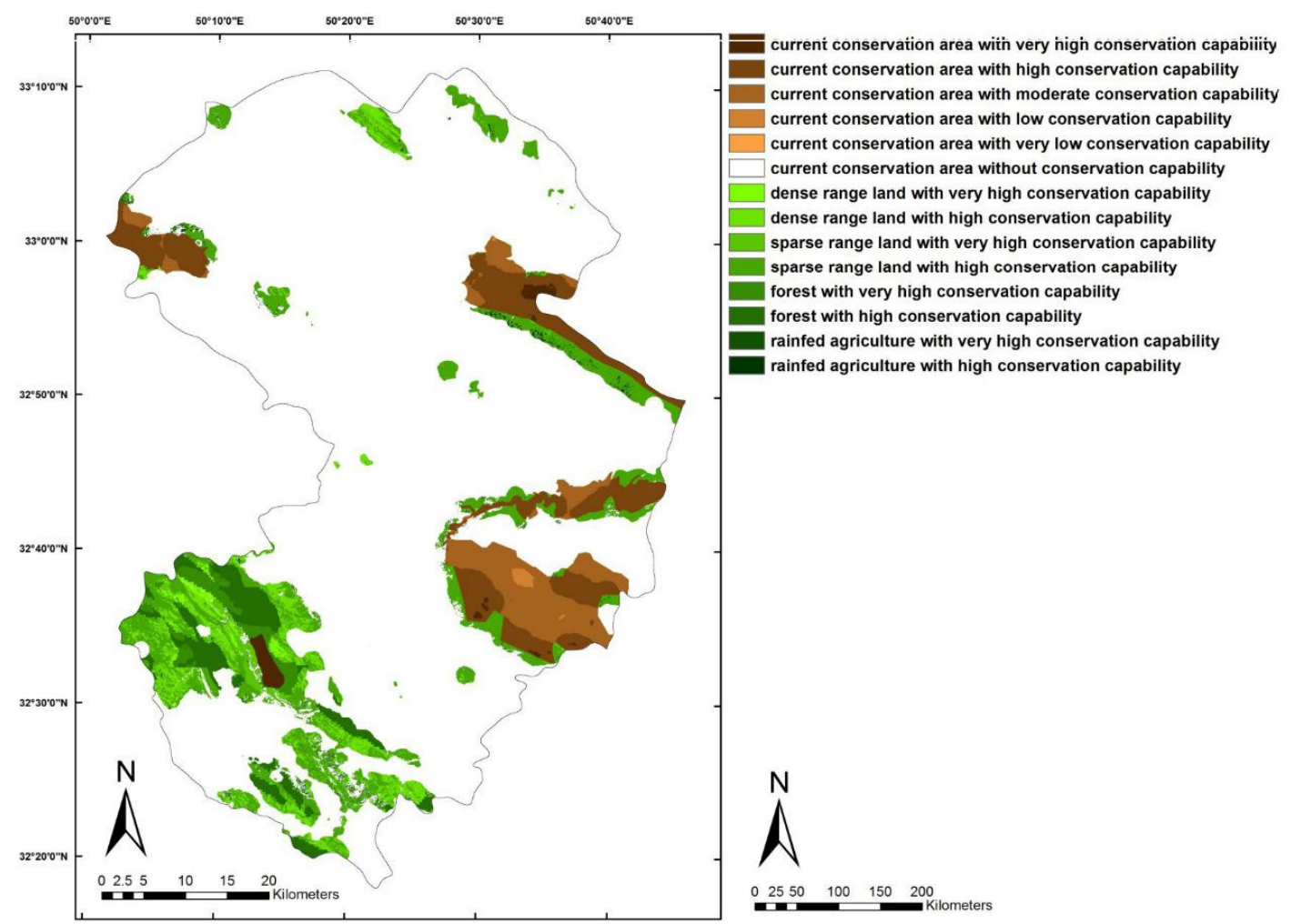

Figure 8. LULC in very high and high conservation capability classes in WLC 


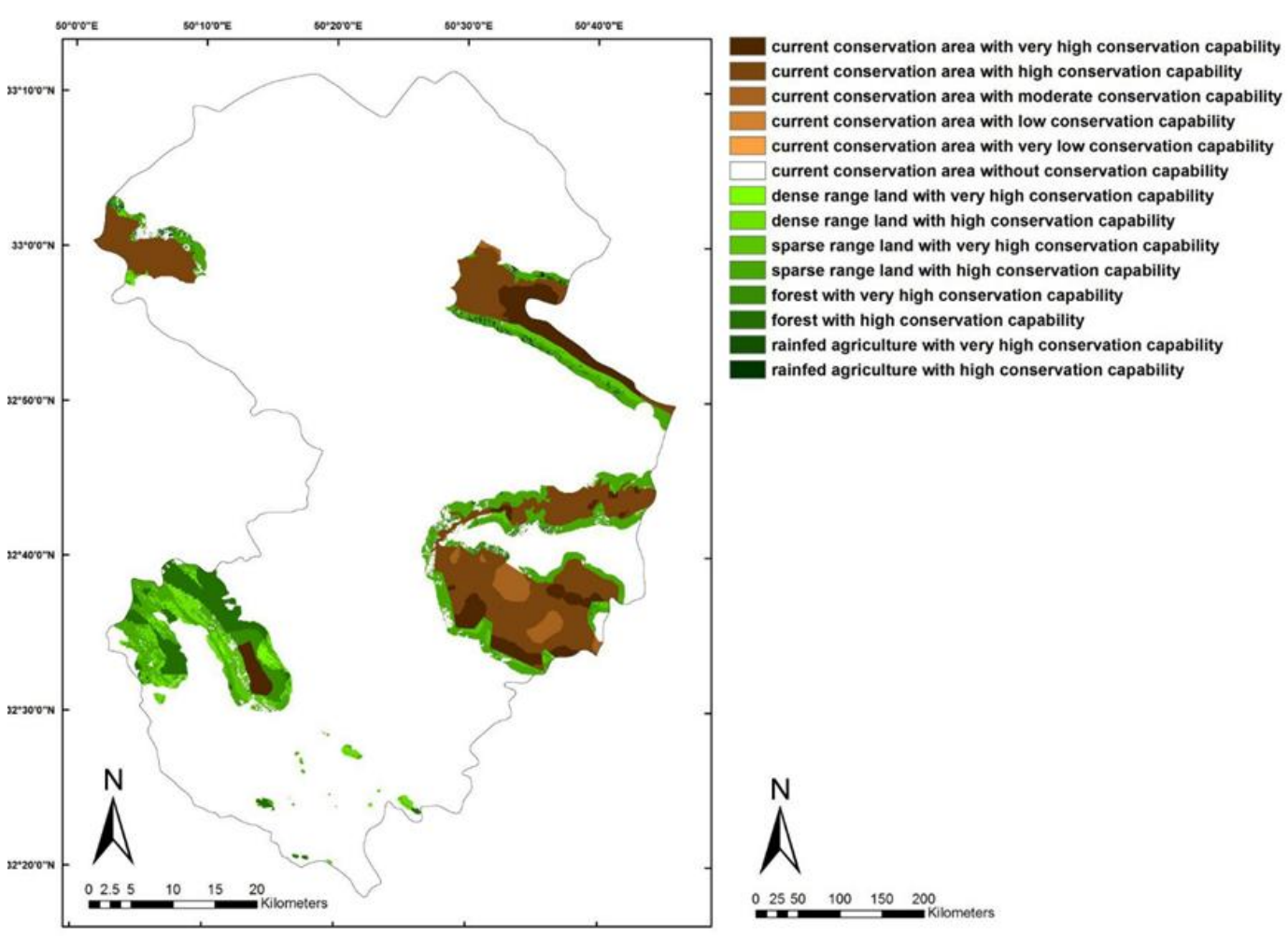

Figure 9. LULC in very high and high conservation capability classes in OWA

Table 4 shows the results of overlaying map of LULC on the conservation capability maps with very high and high classes. In this table, the elements of column represent each LULC class area with very high and high conservation capability with different methods. In this table, LULC classes areas are shown by conservation region and without conservation region. In this case, it becomes clear which LULC are in conservation region.

Table 4 shows which LULCs are proper for selecting as new conservation areas or completing current under conservation areas.

Accuracy assessment of WLC and OWA models has shown that OWA model with an overall accuracy of 0.85 has more accuracy than WLC model with a total accuracy of 0.72 .

\section{Discussion}

In most studies on conservation capability evaluation, researchers have focused on biodiversity elements; and as a result, they have considered a few aspects of conservation (Allahyari et al., 2010). In this study, because of valuable habitats for terrestrial and aquatic animals and the importance of Pelasjan sub-basin in Gavkhooni watershed, as the main source of water for international Gavkhooni wetland, different aspects of conservation such as dispersion of endangered animals like brown bear, panther, wild goat and sheep, flora, and areas with high precipitation were considered in an attempt to prevent from any change in their natural conditions. Moreover, land conservation capability was evaluated by using WLC and OWA combination methods. By considering the same risk level in two models, the effects of trade-off levels were 
investigated on evaluation results (Malcezewski, 2006b; Boroushaki and Malczewski, 2008; Chen and Paydar, 2012; Chen et al., 2013; Sánchez et al., 2013; Zavadskas et al., 2015; Mokarram and Hojati, 2017; Villacreses et al., 2017). Layers weights were prepared using AHP method making it possible to compare relative layers' importance and consistency of pairwise comparison, which made the accuracy of pairwise comparisons possible (Jayanath and Herath, 2009; Hasanzadeh et al., 2013; Maddahi et al., 2014). Table 3 and Figures 6 and 7 show that higher conservation capability areas are in the WLC model because of the higher trade-off level compared to designing OWA model.

Table 4. LULC area and overlaying on land capability map results area (hectare)

\begin{tabular}{|c|c|c|c|c|c|c|c|c|c|}
\hline & $\begin{array}{c}\text { Conservation } \\
\text { area }\end{array}$ & $\begin{array}{c}\text { Dense } \\
\text { range } \\
\text { land }\end{array}$ & $\begin{array}{l}\text { Sparse } \\
\text { range } \\
\text { land }\end{array}$ & Forest & $\begin{array}{c}\text { Irrigated } \\
\text { agriculture }\end{array}$ & $\begin{array}{l}\text { Rain-fed } \\
\text { agriculture }\end{array}$ & $\begin{array}{l}\text { Residential } \\
\text { area }\end{array}$ & $\begin{array}{l}\text { Water } \\
\text { body }\end{array}$ & $\begin{array}{c}\text { Snow } \\
\text { reservoir }\end{array}$ \\
\hline $\begin{array}{l}\text { LULC class } \\
\text { without } \\
\text { conservation } \\
\text { areas }\end{array}$ & 0 & 48830 & 256291 & 11102 & 58029 & 25684 & 4269 & 2654 & 0 \\
\hline $\begin{array}{l}\text { LULC class } \\
\text { with } \\
\text { conservation } \\
\text { areas }\end{array}$ & 41661 & 44788 & 225185 & 10345 & 56096 & 24626 & 4155 & 0 & 6114 \\
\hline $\begin{array}{l}\text { WLC with } \\
\text { very high } \\
\text { capability }\end{array}$ & 8905 & 1240 & 2354 & 3750 & 0 & 63 & 0 & 2654 & 5520 \\
\hline $\begin{array}{l}\text { WLC with } \\
\text { high } \\
\text { capability }\end{array}$ & 28176 & 10169 & 29306 & 9238 & 0 & 1392 & 0 & 0 & 594 \\
\hline $\begin{array}{l}\text { OWA with } \\
\text { very high } \\
\text { capability }\end{array}$ & 4037 & 391 & 3546 & 1470 & 0 & 94 & 0 & 2234 & 4890 \\
\hline $\begin{array}{l}\text { OWA with } \\
\text { high } \\
\text { capability }\end{array}$ & 25194 & 7902 & 20806 & 5773 & 0 & 1245 & 0 & 220 & 1224 \\
\hline
\end{tabular}

Some similarity was expected between categories of a criteria's conservation capability and final conservation capability maps because by decreasing the original weights, the effects of trade-off increase. In order to assess the conservation capability maps, fauna sub-criterion with the highest weight in the ecosystem criterion, which has the highest weight among all criteria, was selected (Feizizadeha et al., 2014; Morshedi and Koravand, 2015).

Comparisons between fauna distribution sub-criterion and the final map of conservation capability produced by medium risk and trade-off in OWA and high tradeoff in WLC models, have shown that because of lower trade-off level in OWA, its result is more similar to the real conditions (fauna distribution). On the other hand, OWA model has considered less area in the first two classes with the highest conservation capability in comparison to WLC results (Table 3). (Malczewski, 2006a; Hajehforooshnia et, al., 2011; Farashi and Shariatic, 2013; Sánchez et al., 2013; Feizizadeha et al., 2014; Morshedi and Koravand, 2015; Farashi et al., 2016).

In Table 4, because some criteria such as irrigated agriculture and residential area (Urban) were constraints and they were used with Boolean logic on land capability maps, they had no capability for conservation. 
Table 4 and Figures 8 and 9 show that some parts of the current conservation areas do not have very high and high capability for conserving due to their proximity to urban areas, mines, or irrigated and rain-fed agriculture.

Accuracy assessment results have shown that designed OWA model in this study with medium risk and trade-off is more accurate than WLC model with the highest risk and trade-off model. Therefore, more trade-off level in WLC models led to lower conservation value in fauna distribution criterion in a pixel to compensate via other criteria, which have more conservation value in that pixel.

\section{Conclusion}

The results of this research indicate that applications of MCE in GIS are multifunctional and can incorporate different levels of complexity of the decision problem. In this case, the choice of ordinary and ranked weights has played a crucial role. It is obvious that decision-makers with a preference for a subjective scale may not arrive at the same weights for the factor criteria. Therefore, experts and stakeholders must be selected carefully. This may lead to different results for suitability maps and can affect the final decision with regard to the overall objective. In AHP method, this can be reduced using calculating consistency coefficient. However, it must be noted that the presented methods are only tools to aid decision-makers; they are not the decisions themselves. For the final point, although OWA model is more similar to each main criterion conservation capability classes, it is suggested that in sensitive areas, especially in watershed water resources like Plasjan sub-basin, because of their important functions in a watershed, there is an increase the risk and trade-off to consider more areas as proper conservation areas. Then, WLC conservation capability evaluation model was suggested in these sensitive areas. As a water reservoir and biodiversity conservation, Pelasjan sub-basin has a very important role in the Gavekhooni basin in the center of Iran. Then, it is highly necessary to consider more areas for conserving its functions and structures; in this research, WLC model results with more trade-off level are more acceptable.

For future studies, we recommend that the effects of weights' uncertainty on land capability evaluation be analyzed.

\section{REFERENCES}

[1] Ahn, B. S. (2008): Preference relation approach for obtaining OWA operators weights. International Journal of Approximate Reasoning 47: 166-178.

[2] Alexander, M. A., Sahotra, S. (2006): Incorporating multiple criteria into the design of conservation area networks: a mini review with recommendations. - Diversity and Distributions 12: 125-137.

[3] Ali Yahyai, S., Charabi, Y., Gastli, A., Al badi, A. (2012): Wind farm land suitability indexing using multi-criteria analysis. - Renewable Energy 44: 80-87.

[4] Allahyari, F., Danehkar, A., Sharifipor, R. (2010): Determining conservation area using ulti criteria spatial evaluation. - Journal of Environmental Geology 13(4): 65-78 (in Persian).

[5] Allaouia, H., Guoa, Y., Choudhary, A., Bloemhof, J. (2018): Sustainable agro-food supply chain design using two-stage hybrid multi-objective decision-making approach. Computers \& Operations Research 89: 369-384. 
[6] Ananda, J., Herath, G., (2009): A critical review of multi-criteria decision making methods with special reference to forest management and planning. - Ecological economics 68(10): 2535-2548.

[7] Boroushaki., S., Malczewski, J. (2008): Implementing an extension of the analytical hierarchy process using ordered weighted averaging operators with fuzzy quantifiers in ArcGIS. - Computers \& Geosciences 34: 399-410.

[8] Bryan, B. A., Grandgirard, A., Ward, J. R., (2009): Managing natural capital and ecosystemservices: Identifying strategic regional priorities in the South Australian Murray-Darling Basin. - CSIRO Water for a Healthy Country National Research Flagship.

[9] Chakhar, S., Mousseau, V. (2008): Spatial Multi Criteria Decision Making. - In: Shehkar, S., Xiong, H. (eds.) Encyclopedia of GIS, pp. 747-753. - Springer, New York.

[10] Chen, Y., Paydar, Z. (2012): Evaluation of potential irrigation expansion using a spatial fuzzy multi-criteria decision framework. - Environmental Modelling \& Software 38: 147-157.

[11] Chen, Y., Yu, J., Khan, S. (2013): The spatial framework for weight sensitivity analysis in AHP-based multi-criteria decision making. - Environmental Modelling \& Software 48: 129-140.

[12] Cheng, C. H., Wang, G. W., Wu, M. C. (2009): OWA-weighted based clustering method for classification problem. - Expert Systems with Applications 36: 4988-4995.

[13] Drobne, S., Lisec, A. (2009): Multi-attribute decision analysis in GIS: weighted linear combination and ordered weighted averaging. - Informatica 33: 459-474.

[14] Estman, J. R. (2001): Guide to GIS and Image Processing Volume. Release 2. - Clark University, USA.

[15] Farashi, A., Naderi, M., Parvin, N. (2016): Identifying a preservation zone using multi criteria decision analysis. - Animal Biodiversity and Conservation 39(1): 29-36.

[16] Feizizadeha, B., Shadman, M., Jankowskic, P., Blaschke, T. (2014): A GIS-based extended fuzzy multi-criteria evaluation for landslide susceptibility mapping. Computers \& Geosciences 73: 208-221.

[17] Hajehforooshnia, S., Soffianian, A., Mahiny, S., Fakheran, S. (2011): Multi objective land allocation (MOLA) for zoning Ghamishloo wildlife sanctuary in Iran. - Journal for Natural Conservation 19: 254-262.

[18] Hajkowicz, S., Collins, K. (2007): A review of multiple criteria analysis for water resourcce planning and management. - Water Resource Management 21(9): 1553-1566.

[19] Hasanzadeh, M., Danehkar, A., Azizi, M. (2013): The application of analytical network process to environmental prioritizing criteria for coastal oil jetties site selection in Persian Gulf coasts (Iran). - Ocean Coast. Manag. 73: 136-144.

[20] Jayanath, A., Herath, A., G. (2009): Critical review of multi-criteria decision making methods with special reference to forest management and planning. - Ecological Economics 68: 2535-2548.

[21] Jiang, H., Eastman, J. R. (2000): Application of fuzzy measures in multi-criteria evaluation in GIS. - International Journal of Geographical Information Systems 14(2): 173-184.

[22] Kristof, G. M., (2005): Planning Business Improvement Using Analytic Hierarchy Process and Design structure Matrix. - Master Thesis, Montana State University, Bozeman.

[23] Maddahi, Z., Jalalian, A., Zarkesh, M. M. K., Honarjo, N. (2014): Land suitability analysis for rice cultivation using multi criteria evaluation approach and GIS. - European Journal of Experimental Biology 4(3): 639-648.

[24] Makropoulos, C. K., Butler, D. (2006): Spatial ordered weighted averaging: incorporating spatially variable attitude towards risk in spatial multi-criteria decision-making. Environmental Modelling \& Software 21(1): 69-84. 
[25] Malczewski, J. (2004): GIS-based land-use suitability analysis: a critical overview. Progress in Planning 62(1): 3-65.

[26] Malcezewski, J. (2006): Ordered weighted averaging with fuzzy quantifier GIS-based multi-criteria evaluation for land-use suitability analysis. - International Journal for Applied Earth Observation and Geoinformation 8: 270-277.

[27] Malczewski, J. (2006): GIS-based multi criteria decision analysis: a survey of the literature. - International Journal of Geographical Information Science 20(7): 703-726.

[28] Mirghaed, F. A., Sori, B., Pirbavaghar, M. (2014): Using fuzzy simple additive weight (FSAW) for land evaluation in order to determining area with conservation capability in parcel A, Gheshlagh dam basin. - Journal of Environmental Science and Technology 16: 273-280 (in Persian).

[29] Moeinaddini, M., Khorasani, N., Danehkar, A., Darvishsefat, A. A., Zienalyan, M. (2010): Siting MSW landfill using weighted linear combination and analytical hierarchy process (AHP) methodology in GIS environment (case study: Karaj). - Waste Manag. 30(5): 912e920.

[30] Mokarram, M., Hojati, M. (2017): Using ordered weight averaging (OWA) aggregation for multi-criteria soil fertility evaluation by GIS (case study: southeast Iran). - Computers and Electronics in Agriculture 44(132): 1-13.

[31] Morshedi, J., Koravand, A. (2015): Suitable lands site selection for amygdalus scoparia implant using GIS technology and AHP method in Mordghafar watershed Izae township. - Journal of Wetland Eco-Biology 7(26): 69-86 (in Persian).

[32] Mosadeghi, R. (2013): A Spatial Multi-Criteria Decision Making Model of Coastal Land Use Planning. - PhD Thesis, Griffirth School of Environment, Griffith University, Australia.

[33] Mosadeghi, R., Warnken, J., Tomlinson, R., Mirfenderesk, H. (2015). Comparison of Fuzzy-AHP and AHP in a spatial multi-criteria decision making model for urban land-use planning, Computers. - Environment and Urban Systems 49: 54-65.

[34] Mousavi, M., Yazdani, C. R. (2014): Land use suitability analysis using AHP-OWA for Tabriz city. - Journal of Geography and Urban Planning Resource 3: 361-381(in Persian).

[35] Mousavi, S. H., Danehkarb, A., Shokric, M. R., Poorbagherd, H., Azhdarie, D. (2015): Site selection for artificial reefs using a new combine Multi-Criteria Decision-Making (MCDM) tools for coral reefs in the Kish Island - Persian Gulf. - Ocean \& Coastal Management 111: 92-102.

[36] Norris, G. A., Marshall, H. E. (1995): Multiattribute Decision Analysis Method for Evaluating Buildings and Building Systems. - Building and Fire Research Laboratory. US National Institute of Standards and Technology, Gaithersburg, MD 20899.

[37] Parhizkar, A., Ghaffari, A. (2011): GIS and Multi Criteria Decision Analysis. - Samt Press, Tehran (in Persian).

[38] Sánchez-Lozano, J. M., Teruel-Solano, J., Soto-Elvira, P. L., García-Cascales, M. S. (2013): Geographical Information Systems (GIS) and Multi-Criteria Decision Making (MCDM) methods for the evaluation of solar farms locations: Case study in south-eastern Spain. - Renewable and Sustainable Energy Reviews 24: 544-55.

[39] Satty, L. (1994): The Analytic Hierarchy Process. 1st edition. - Mcgraw-Hill, New York, USA.

[40] Seok, A. B. (2008): Preference relation approach for obtaining OWA operators weights. International Journal of Approximate Reasoning 47: 166-178.

[41] Villacreses, G., Gaona, G., Martínez-Gomez, J., Juan Jijon, D. (2017): Wind farms suitability location using geographical information system (GIS), based on multi-criteria decision making (MCDM) methods: The case of continental Ecuador. - Renewable Energy 109: 275-286.

[42] Zavadskas, E. K., Tusrkis, Z., Bagocius, V. (2015): Multi-criteria selection of a deepwater port in the Eastern Baltic Sea. - Applied Soft Computing 26: 180-192. 